\title{
Chronic AT1 blockade improves glucose homeostasis in obese OLETF rats
}

\author{
Ruben Rodriguez', Jacqueline N Minas', Jose Pablo Vazquez-Medina², Daisuke Nakano², David G Parkes4, \\ Akira Nishiyama ${ }^{3}$ and Rudy M Ortiz ${ }^{1}$
}

\author{
1Department of Molecular \& Cellular Biology, University of California, Merced, California, USA \\ 2Department of Integrative Biology, University of California, Berkeley, California, USA \\ 3Department of Pharmacology, Kagawa University Medical School, Kagawa, Japan \\ ${ }^{4}$ DGP Scientific Inc., Del Mar, California, USA
}

Correspondence should be addressed to R Rodriguez: rrodriguez3@ucmerced.edu

\section{Abstract}

Obesity is associated with the inappropriate activation of the renin-angiotensin system (RAS), which increases arterial pressure, impairs insulin secretion and decreases peripheral tissue insulin sensitivity. RAS blockade reverses these detriments; however, it is not clear whether the disease state of the organism and treatment duration determine the beneficial effects of RAS inhibition on insulin secretion and insulin sensitivity. Therefore, the objective of this study was to compare the benefits of acute vs chronic angiotensin receptor type $1\left(\mathrm{AT}_{1}\right)$ blockade started after the onset of obesity, hyperglycemia and hypertension on pancreatic function and peripheral insulin resistance. We assessed adipocyte morphology, glucose intolerance, pancreatic redox balance and insulin secretion after 2 and 11 weeks of AT $_{1}$ blockade in the following groups of rats: (1) untreated Long-Evans Tokushima Otsuka (lean control; $n=10)$, (2) untreated Otsuka Long-Evans Tokushima Fatty (OLETF; $n=12$ ) and (3) OLETF + ARB (ARB; $10 \mathrm{mg}$ olmesartan $/ \mathrm{kg} /$ day by oral gavage; $n=12$ ). Regardless of treatment duration, $\mathrm{AT}_{1}$ blockade decreased systolic blood pressure and fasting plasma triglycerides, whereas chronic $\mathrm{AT}_{1}$ blockade decreased fasting plasma glucose, glucose intolerance and the relative abundance of large adipocytes by 22,36 and $70 \%$, respectively. AT ${ }_{1}$ blockade, however, did not improve pancreatic oxidative stress or reverse impaired insulin secretion. Collectively, these data show that $\mathrm{AT}_{1}$ blockade after the onset of obesity, hyperglycemia and hypertension improves peripheral tissue insulin sensitivity, but cannot completely reverse the metabolic derangement characterized by impaired insulin secretion once it has been compromised.

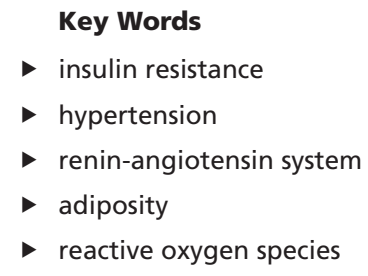

Journal of Endocrinology (2018) 237, 271-284

\section{Introduction}

Obesity affects $35 \%$ of males and $40 \%$ of females in the United States (Flegal etal.2016) and predisposes individuals to the development of cardiovascular disease (CVD) (Gaal et al. 2006) and type 2 diabetes mellitus (T2DM) (Kahn et al. 2006). Another detriment of obesity is the inappropriate activation of the renin-angiotensin system (RAS) (Engeli et al. 2005). Inappropriately activated RAS disrupts the actions of insulin in peripheral tissues. In L6 and primary myotubes, elevated angiotensin II (Ang II) levels decrease insulin-stimulated glucose uptake and glucose transporter 4 
(GLUT4) translocation (Wei et al. 2006, 2008, Csibi et al. 2010). In primary human preadipocytes, elevated Ang II levels decrease cell differentiation, leading to the formation of large adipocytes (Janke et al. 2002), while in male Wistar rats, elevated Ang II levels increase hepatic glucose output (Rao 1996). Ultimately these events may contribute to the development of T2DM. On the contrary, angiotensin-converting enzyme inhibitors (ACEis) and angiotensin receptor blockers (ARBs) reduced the onset of T2DM in individuals with cardiovascular risk factors or CVD (McMurray et al. 2010, Tocci et al. 2011). Moreover, in individuals without CVD, but with impaired fasting glucose or glucose intolerance, treatment with an ACEi increased the regression to normoglycemia (Bosch et al. 2006), suggesting that the state of the disease at the onset of RAS inhibition may determine the effectiveness of the intervention on glucose regulation.

Healthy $\beta$-cells compensate for glucose intolerance and insulin resistance by insulin hypersecretion. However, $\beta$-cell dysfunction, the inability of $\beta$-cells to sustain this compensatory response, ultimately leads to the development of T2DM. Many factors such as elevated Ang II levels may result in $\beta$-cell dysfunction (Chu et al. 2006, Lastra et al. 2007, Habibi et al. 2008, Chhabra et al. 2013, Sauter et al. 2015). Elevated Ang II levels also increase the expression and activity of the oxidant-generating enzyme NADPH oxidase 2 (Nox2) in L6 myotubes (Wei et al. 2006, Lastra et al. 2007). To manage tolerable levels of oxidants, antioxidant enzymes such as superoxide dismutase (SOD) neutralize elevated levels of superoxide. Pancreatic islets of male Wistar rats contain moderate but physiologically sufficient levels of SOD in the cytoplasm and mitochondria (Tiedge et al. 1997). However, levels of the hydrogen peroxide removing enzymes, glutathione peroxidase (GPx) and catalase, are extremely low in pancreatic islets, composing less than $1 \%$ of the expression levels in the liver (Tiedge et al. 1997). Consequently, excessive generation of reactive oxygen species impairs $\beta$-cell function, leading to decreased glucose-stimulated insulin secretion (GSIS) (Li et al. 2012). Nevertheless, this condition was reversed by $\mathrm{AT}_{1}$ blockade in young $d b / d b$ mice (Chu et al. 2007), suggesting that activation of $\mathrm{AT}_{1}$ contributes to the manifestation of insulin resistance via oxidative injury to the pancreas and associated impaired GSIS. However, the degree to which $\mathrm{AT}_{1}$ blockade can correct the pancreatic dysfunction present during the later progression of insulin resistance and early onset T2DM is not well established.

Although there has been substantial progress in delineating the mechanisms by which RAS activation impairs pancreatic $\beta$-cell function and peripheral insulin signaling, whether the disease state of the organism and treatment duration determine the beneficial effects of RAS inhibition is unknown. The objective of this study was to compare the benefits of acute and chronic $\mathrm{AT}_{1}$ blockade started after the onset of obesity, hyperglycemia and hypertension on pancreatic function and peripheral insulin resistance. Using Otsuka Long-Evans Tokushima Fatty (OLETF) rats, a model characterized by hyperphagia, obesity, hyperglycemia, hypertension, dyslipidemia and elevated RAS (Kawano et al. 1992, Nishiyama et al. 2008, Montez et al. 2012), we tested the hypothesis that chronic $\mathrm{AT}_{1}$ blockade after the onset of obesity, hyperglycemia and hypertension decreases fasting plasma glucose and glucose intolerance by improving adipocyte morphology, and that these effects are independent of improvements in pancreatic function.

\section{Materials and methods}

Detailed methods are available in the Supplementary Methods (see section on supplementary data given at the end of this article).

All experimental procedures were reviewed and approved by the institutional animal care and use committees of Kagawa Medical University (Kagawa, Japan) and the University of California, Merced (Merced, CA, USA).

\section{Animals}

Eight-week-old male, Long-Evans Tokushima Otsuka (LETO) and OLETF rats were studied (Japan SLC Inc., Hamamatsu, Japan). Rats were randomly assigned to their study groups based on body mass (BM), so that mean BM in each group was within 5\% of each other at the onset. The study groups were: (1) untreated LETO (lean control; $n=5 /$ time point $)+$ vehicle $(0.5 \%$ methylcellulose by oral gavage once daily; $1 \mu \mathrm{L} / g)$, (2) untreated OLETF $(n=6 /$ time point)+vehicle and (3) OLETF+ARB (ARB; $10 \mathrm{mg}$ olmesartan/kg/day by oral gavage at a volume of $1 \mu \mathrm{L} / \mathrm{g}$; for 2 or 11 weeks; $n=6 /$ time point). For ARB administration, olmesartan was suspended in distilled water using $0.5 \%$ methylcellulose to achieve a concentration of $10 \mathrm{mg} / \mathrm{mL}$ and was kept at $4^{\circ} \mathrm{C}$ for less than 5 days. The two ARB dosing regiments represented acute (2 weeks) and chronic (11 weeks) treatments. All animals were housed in a specific pathogen-free facility under controlled temperature $\left(23^{\circ} \mathrm{C}\right)$ and humidity (55\%) with a 12-h light, 
12-h darkness cycle. All animals had free access to water and standard laboratory rat chow consisting of 5\% fat, $24 \%$ protein and 54\% carbohydrates (MF; Oriental Yeast Corp., Tokyo, Japan).

\section{Oral glucose tolerance test (oGTT)}

At $-4,2$ and 11 weeks, following a 12-h fast (21:0009:00 h), oGTTs were performed 09:00-12:00 h to assess glucose tolerance as previously described (Rodriguez et al. 2012). The positive incremental areas under the curve for glucose ( $\left.\mathrm{AUC}_{\text {glucose }}\right)$ and insulin $\left(\mathrm{AUC}_{\text {insulin }}\right)$ were calculated by the trapezoidal method (Allison et al. 1995) and used to calculate the insulin resistance index (IRI).

\section{Pancreatic insulin and insulin secretion}

For the measurement of total pancreatic insulin, $80 \mathrm{mg}$ of frozen pancreatic tissue was homogenized in $250 \mu \mathrm{L}$ of cold RIPA buffer, containing PIC (Thermo Fisher Scientific, Waltham, MA). The homogenized tissue was centrifuged $\left(20,000 \mathrm{~g} \times 10 \mathrm{~min}\right.$ at $\left.4^{\circ} \mathrm{C}\right)$, and the aqueous layer was transferred to a separate tube and stored at $-80^{\circ} \mathrm{C}$ for later analysis. Insulin secretion was calculated using the total area under the curve (AUC) for insulin divided by the total AUC for glucose from the oGTT as previously described (Retnakaran et al. 2008, Maki et al. 2009).

\section{Western blot}

Cytosolic and membrane proteins were extracted as previously described (Viscarra et al. 2011) and assayed as described in the Supplementary Methods. Membranes were scanned in an Odyssey infrared imager (LI-COR Biosciences, Lincoln, NE, USA).

\section{Statistics}

Means ( \pm s.E.) were calculated using all samples unless otherwise noted. Baseline measurements were compared using an independent sample $t$-test. We used a one-way ANOVA at each time point for adiposity measurements with treatment group as a between-subject factor. For non-esterified fatty acids (NEFA) measurements following an oGTT, we used a three-factor ANOVA with group and time (weeks) as between-subject factors and time after administration as a within-subject factor. For all other data, we used a two-factor ANOVA with group and time as between-subject factors unless otherwise specified in the figure legend. When significant differences were observed, pairwise comparisons were carried out using a Bonferroni correction. Glucose tolerance was assessed by comparing mean AUC values obtained from the glucose profiles during the oGTTs. Statistical significance was set at $P<0.05$. Statistical analyses were performed with SPSS version 24 (IBM).

\section{Results}

\section{Baseline characteristics of OLETF rats}

Food intake, fasting plasma glucose (FPG), triglycerides (TG), NEFA, glucose tolerance, insulin secretion and the IRI were measured to assess the disease state at the onset of the study before intervention. At baseline, OLETF rats were characterized by higher food intake and FPG as compared to LETO (Supplementary Table 1).

\section{Effects of AT, blockade on SBP and heart rate}

SBP and heart rate were measured to assess the effects of $\mathrm{AT}_{1}$ blockade on cardiovascular function. SBP measured by tail cuff: SBP was greater at baseline in OLETF compared to LETO and remained elevated for the duration of the study. $\mathrm{AT}_{1}$ blockade decreased SBP at 2 weeks and remained lower throughout the study (Fig. 1A). Heart rate measure by tail cuff: There was a significant time, but not group effect on heart rate. Mean heart rate decreased with time (Fig. 1B). SBP measured by telemetry: SBP was greater at -3 weeks in OLETF compared to LETO, and $\mathrm{AT}_{1}$ blockade normalized it (Supplementary Fig. 1). However, because of the loss of battery life in most telemeters, comparisons could only be made until 5 weeks (Supplementary Fig. 1).

\section{Chronic $\mathrm{AT}_{1}$ blockade decreases fasting plasma glucose}

FPG, TG, NEFA, adiponectin and IRI were measured to assess whether the timing of $\mathrm{AT}_{1}$ blockade influenced the biochemical parameters of metabolic syndrome and systemic insulin resistance. At 2 weeks, mean FPG was $51 \%$ greater in OLETF compared to LETO, and ARB had no significant effect. At 11 weeks, mean FPG was 63\% higher in OLETF compared to LETO, and ARB reduced it $22 \%$ compared to OLETF (Table 1 ). There was a significant group, but not time effect on TG. Mean TG was greater in OLETF compared to LETO, while ARB reduced them (Table 1). At 2 weeks, mean plasma NEFA were 56\% higher in OLETF compared to LETO, while ARB had no significant effect (Table 1). At 11 weeks, mean plasma 
A
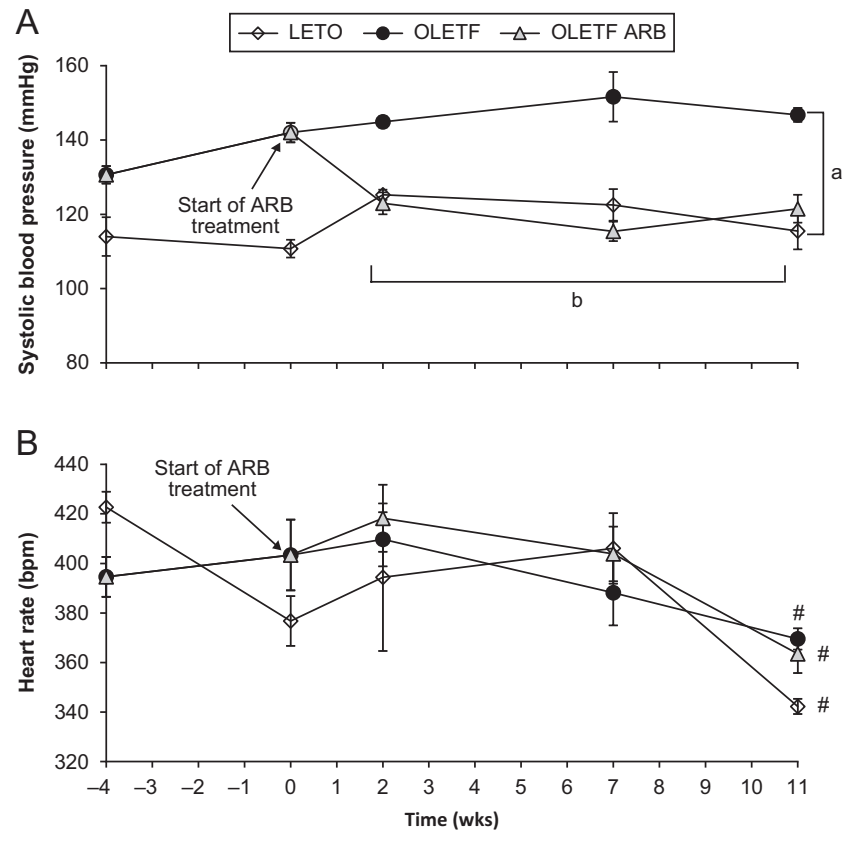

Figure 1

$\mathrm{AT}_{1}$ blockade decreases systolic blood pressure. Mean ( \pm s.E.) (A) systolic blood pressure and (B) heart rate measured by tail cuff of Long-Evans Tokushima Otsuka (LETO; $n=4)$, Otsuka Long-Evans Tokushima Fatty (OLETF; $n=5)$ and OLETF+ARB $(n=5)$. Comparisons were assessed using a two-factor ANOVA with group as a between-subjects factor and time as a withinsubjects factor. $P^{P}<0.05$ vs LETO; ${ }^{b} P<0.05$ vs OLETF; ${ }^{P} P<0.05$ vs baseline.

NEFA were not different among the groups (Table 1). There was a significant time, but not group effect on plasma adiponectin. Mean plasma adiponectin decreased with time (Table 1). At 2 weeks, mean IRI was not different among the groups (Table 1). At 11 weeks, mean IRI was 3.7-fold greater in OLETF compared to LETO, and ARB normalized it (Table 1). Collectively, these data demonstrate that the improvements of parameters related to metabolic syndrome are independent of the timing or duration of $\mathrm{AT}_{1}$ blockade, except FPG and IRI, which improved only after chronic blockade.

\section{The metabolic syndrome-like phenotype is associated with oxidative stress and impaired antioxidant capacity in the pancreas}

Markers of oxidative damage and antioxidant enzyme activities were measured to assess the effects of the metabolic syndrome-like phenotype and $\mathrm{AT}_{1}$ signaling on pancreatic redox balance. There was a significant group, but not time effect on pancreatic lipid peroxidation (4-HNE levels). Mean 4-HNE levels were higher in OLETF compared to LETO, and ARB had no significant effect (Fig. 2A). Mean pancreatic nitrotyrosine levels did not change among the groups or different time points (data not shown). There was a significant group, but not time effect on pancreatic SOD, catalase and GPx activities. Mean SOD, catalase and GPx activities decreased in OLETF compared to LETO, and ARB had no significant effect (Fig. 2B, C and D). Collectively, these data demonstrate that the metabolic syndrome-like phenotype is associated with suppression of pancreatic antioxidant capacity and increased lipid peroxidation and is unaffected by $\mathrm{AT}_{1}$ blockade.

\section{The metabolic syndrome-like phenotype is associated with blunted insulin secretion}

Pancreatic insulin content, glucose transporter 2 (Glut 2) expression and insulin secretion were measured to assess the effects of a pro-oxidant environment and $\mathrm{AT}_{1}$ signaling on pancreatic function. There were no group or time effects on pancreatic Glut 2 protein expression (data not shown). At 2 weeks, mean pancreatic insulin content was 2.9-fold greater in OLETF compared to LETO,

Table 1 Mean ( \pm S.E.) morphometrical, biochemical and hormone measurements in LETO, OLETF and OLETF + ARB male rats.

\begin{tabular}{|c|c|c|c|c|c|c|}
\hline & \multicolumn{3}{|c|}{2 weeks } & \multicolumn{3}{|c|}{11 weeks } \\
\hline & LETO $(n=5)$ & OLETF $(n=6)$ & OLETF ARB $(n=6)$ & LETO $(n=5)$ & $\operatorname{OLETF}(n=6)$ & OLETF ARB $(n=6)$ \\
\hline $\mathrm{FI}(\mathrm{g})$ & $17.7 \pm 0.5$ & $25.2 \pm 0.7^{a}$ & $24.3 \pm 0.9 a$ & $19.4 \pm 0.5$ & $29.3 \pm 1.1^{\mathrm{a}}$ & $26.8 \pm 0.3^{a}$ \\
\hline Retro fat mass $(\mathrm{g})^{*}$ & $4.5 \pm 0.4$ & $11.4 \pm 1.1 c$ & $10.8 \pm 1.7 c$ & $7.7 \pm 0.5$ & $23.9 \pm 2.0 \mathrm{e}$ & $16.8 \pm 1.8^{e, f}$ \\
\hline Epi fat mass $(\mathrm{g})^{*}$ & $4.6 \pm 0.6$ & $9.7 \pm 0.9 c$ & $7.1 \pm 1.0$ & $7.8 \pm 0.7$ & $13.9 \pm 1.0 \mathrm{e}$ & $11.6 \pm 1.1$ \\
\hline Glucose (mmol/L) & $4.1 \pm 0.3$ & $6.2 \pm 0.1^{c}$ & $6.4 \pm 0.4^{c}$ & $4.1 \pm 0.3$ & $6.7 \pm 0.6^{e}$ & $5.2 \pm 0.2^{f, h}$ \\
\hline TG $(\mathrm{mmol} / \mathrm{L})$ & $0.6 \pm 0.1$ & $1.1 \pm 0.1^{a}$ & $0.8 \pm 0.1^{a, b}$ & $0.4 \pm 01$ & $1.3 \pm 0.2^{a}$ & $0.9 \pm 0.1^{a, b}$ \\
\hline NEFA (mEq/L) & $0.57 \pm 0.05$ & $0.89 \pm 0.07 c$ & $0.79 \pm 0.04 c$ & $0.63 \pm 0.05$ & $0.71 \pm 0.04 \mathrm{~g}$ & $0.80 \pm 0.10$ \\
\hline Adiponectin $(\mu \mathrm{g} / \mathrm{mL})$ & $2.43 \pm 0.11$ & $2.92 \pm 0.32$ & $3.08 \pm 0.32$ & $1.90 \pm 0.10^{\S}$ & $2.50 \pm 0.18^{\S}$ & $2.07 \pm 0.13^{\S}$ \\
\hline IRI (r.u. × 106) & $4.2 \pm 1.9$ & $4.9 \pm 1.4$ & $9.1 \pm 3.3$ & $3.5 \pm 8.6$ & $16.5 \pm 4.8^{e, g}$ & $4.2 \pm 1.6^{f}$ \\
\hline
\end{tabular}

Comparisons were assessed using a two-factor ANOVA with group and time as between-subject factors; *, comparisons were assessed using a one-way ANOVA at each time point.

Main effects: a $P<0.05$ vs LETO; ${ }^{b} P<0.05$ vs OLETF; $\$ P<0.05$ vs 2 weeks. Pairwise comparisons: $c P<0.05$ vs LETO 2 weeks; $P$ P $<0.05$ vs LETO 11 weeks; $f P<0.05$ vs OLETF 11 weeks; $9 P<0.05$, OLETF 2 weeks vs OLETF 11 weeks; ${ }^{h} P<0.05$, OLETF ARB 2 weeks vs OLETF ARB 11 weeks. $\mathrm{BM}$, body mass; FI, food intake; IRI, insulin resistance index; NEFA, non-esterified fatty acids; TG, triglycerides.

$\begin{array}{lr}\text { http://joe.endocrinology-journals.org } & \odot 2018 \text { Society for Endocrinology } \\ \text { https://doi.org/10.1530/JOE-17-0678 } & \text { Published by Bioscientifica Ltd. } \\ & \text { Printed in Great Britain }\end{array}$
Printed in Great Britain 


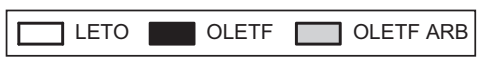

A

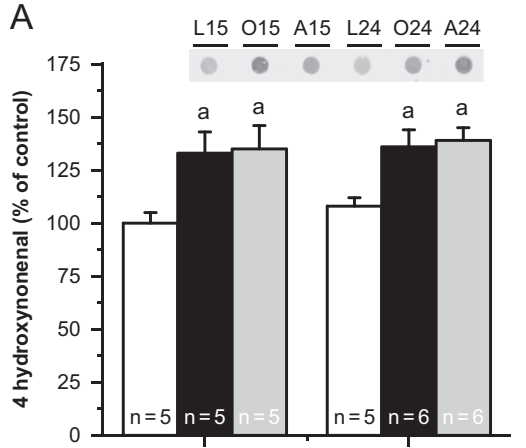

C

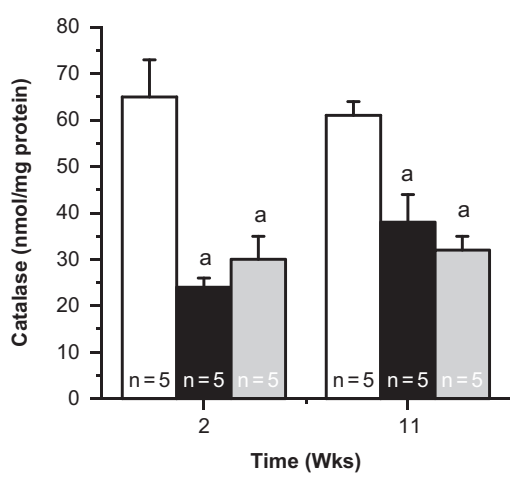

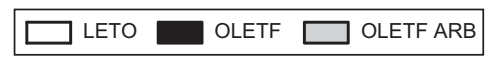

B

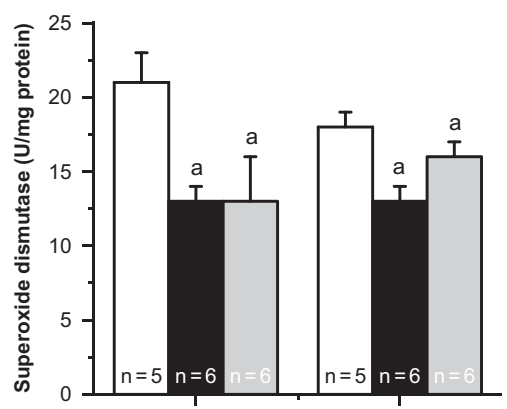

D

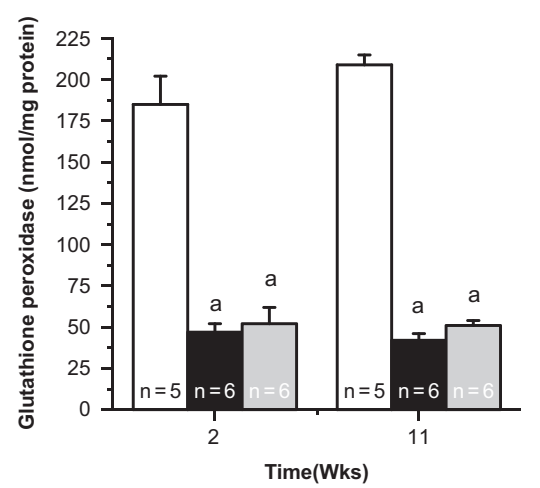

\section{Figure 2}

Effects of $A T_{1}$ blockade on redox balance in the pancreas. Mean ( \pm S.E.) (A) 4-hydroxynonenal and the representative dot blot, (B) activity of pancreatic superoxide dismutase (C) catalase and (D) glutathione peroxidase in pancreas of Long-Evans Tokushima Otsuka (LETO), Otsuka Long-Evans Tokushima Fatty (OLETF) and OLETF+ARB. Comparisons were assessed using a two-factor ANOVA with group and time as between-subject factors. ${ }^{a}<<0.05$ vs LETO. and ARB normalized it (Fig. 3A). There was a significant group, but not time effect on insulin secretion. Mean insulin secretion was reduced in OLETF compared to LETO, and ARB had no significant effect (Fig. 3B). Collectively, these results suggest that $\mathrm{AT}_{1}$ blockade started after the onset of obesity, hyperglycemia and hypertension is not able to recover impaired pancreatic insulin secretory capacity.

\section{Effects of $\mathrm{AT}_{1}$ blockade on adiposity and adipocyte morphology}

BM, Food intake, retroperitoneal and epididymal fat masses, and adipocyte morphology were measured to assess whether the timing of $\mathrm{AT}_{1}$ blockade influenced the beneficial effects on BM and adipocyte morphology. Mean weekly BM was greater at -4 weeks in OLETF compared to LETO, remaining so for the duration of the study (Fig. 4A). $\mathrm{AT}_{1}$ blockade regardless of treatment duration had no significant effect compared to OLETF (Fig. 4A). We further evaluated the gain in BM during the treatment durations. There were significant group and time effects on gain in BM during treatment. At 2 and 11 weeks, the gain in BM during the treatment was greater in OLETF compared to LETO, and ARB treatment normalized it
(Fig. 4B). At 2 weeks, retroperitoneal and epididymal fat masses were greater in OLETF compared to LETO, and ARB had no significant effect compared to OLETF (Table 1). At 11 weeks, retroperitoneal and epididymal fat masses were greater in OLETF compared to LETO, while ARB reduced retroperitoneal fat mass 30\% (Table 1 ). There was a significant group, but not time effect on food intake. Mean food intake was greater in OLETF compared to LETO (Table 1). At 2 weeks, the relative abundance of adipocytes between 25-50 and 101-200 $\mu \mathrm{m}$ were 65\% lower and 14.5fold greater, respectively, in OLETF compared to LETO, and ARB had no significant effect compared to OLETF (Fig. 5A and B). At 11 weeks, the relative abundance of adipocytes between $25-50$ and $51-100 \mu \mathrm{m}$ was 53\% and $22 \%$, respectively, lower in OLETF compared to LETO. The relative abundance of adipocytes between 51 and $100 \mu \mathrm{m}$ was normalized in ARB (Fig. 5A and C). The relative abundance of adipocytes between 101 and $200 \mu \mathrm{m}$ was 9-fold greater in OLETF compared to LETO, and ARB reduced it 70\% compared to OLETF (Fig. 5A and C). Collectively, these data demonstrate that ARB treatment reduced gain in $\mathrm{BM}$ regardless of treatment duration, but only chronic ARB decreased retroperitoneal fat mass and improved adipocyte morphology. 

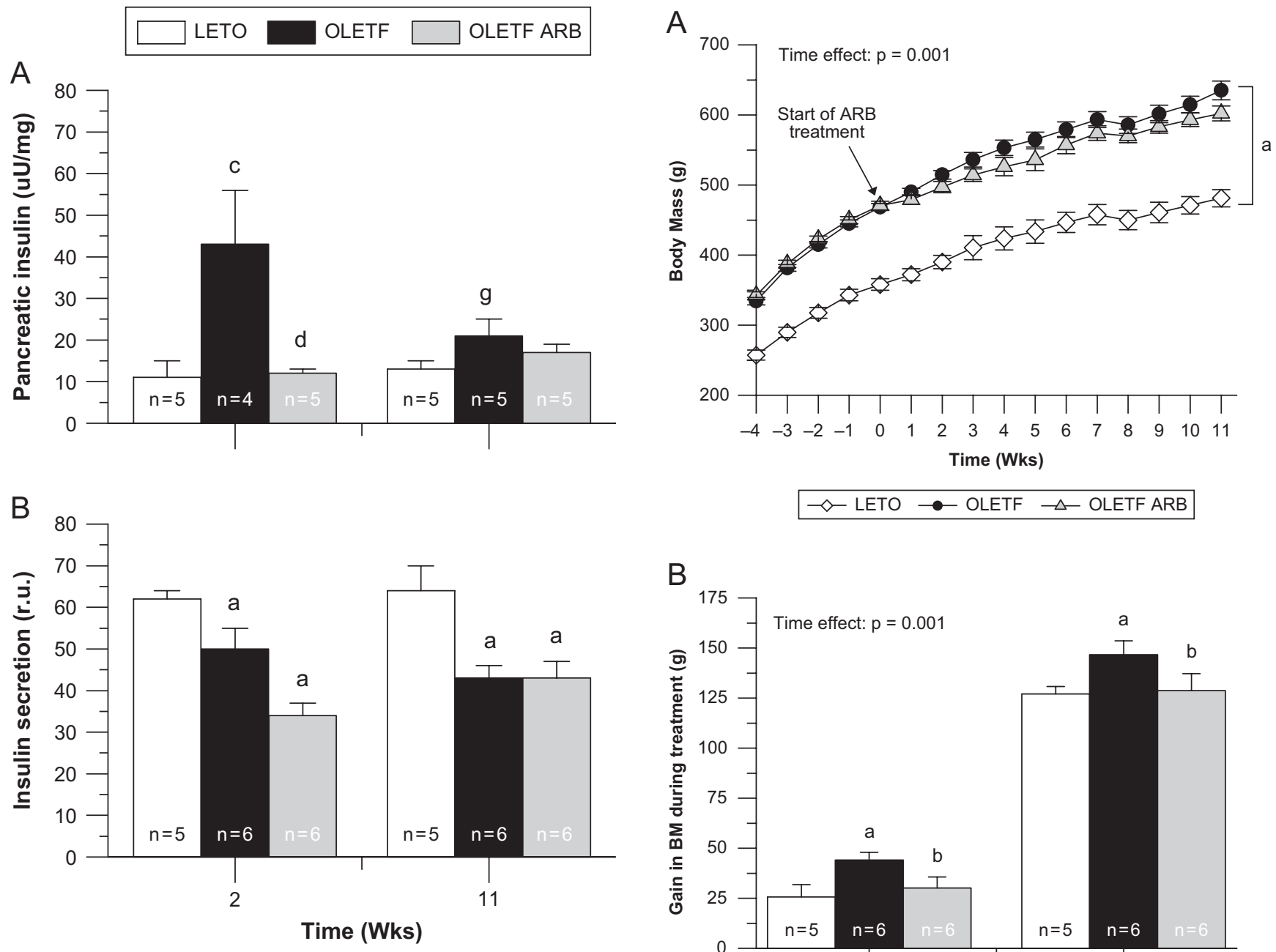

Figure 3

Metabolic syndrome blunts insulin secretion. Mean ( \pm s.E.) (A) pancreatic insulin, and (B) insulin secretion of Long-Evans Tokushima Otsuka (LETO), Otsuka Long-Evans Tokushima Fatty (OLETF) and OLETF ARB.

Comparisons were assessed using a two-factor ANOVA with group and time as between-subject factors. a $P<0.05$ vs LETO; $P<0.05$ vs LETO 2 weeks; $\mathrm{d} P<0.05$ vs OLETF 2 weeks; $9 P<0.05$, OLETF 2 weeks vs OLETF 11 weeks.

\section{TNF- $\alpha$ does not contribute to insulin resistance in OLETF rats}

Plasma tumor necrosis factor-alpha (TNF- $\alpha$ ) and epididymal fat transmembrane TNF- $\alpha$ were measured to assess the effects of decreased adiposity associated with chronic $\mathrm{AT}_{1}$ blockade on systemic and local inflammation. There were no group or time effects on plasma TNF- $\alpha$ (Fig. 6A). There were significant group and time effects on transmembrane TNF- $\alpha$. Mean transmembrane TNF- $\alpha$ was not different between LETO and OLETF; nonetheless, ARB increased it compared to LETO (Fig. 6B). These results suggest that neither systemic nor local TNF- $\alpha$ contribute to the development of insulin resistance in obese OLETF rats.

\begin{tabular}{|lr}
\hline http://joe.endocrinology-journals.org & @ 2018 Society for Endocrinology \\
https://doi.org/10.1530/JOE-17-0678 & Published by Bioscientifica Ltd. \\
Printed in Great Britain
\end{tabular}

B

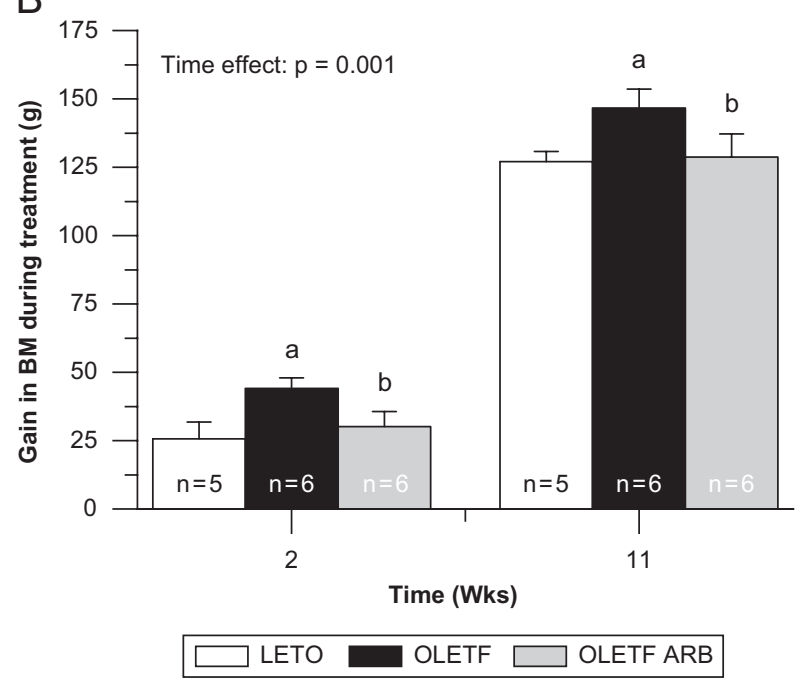

Figure 4

$A T_{1}$ blockade decreases gain in BM. Mean ( \pm S.E.) (A) weekly BM and (B) gain in BM during treatment of Long-Evans Tokushima Otsuka (LETO), Otsuka Long-Evans Tokushima Fatty (OLETF) and OLETF+ARB.

Comparisons were assessed using a two-factor ANOVA with group as a between-subjects factor and time as a within-subjects factor for $(A)$ and with group and time as between-subject factors for (B). a $P<0.05$ vs LETO; b $P<0.05$ vs OLETF.

\section{Chronic $\mathrm{AT}_{1}$ blockade ameliorates the progression of glucose intolerance in OLETF rats}

oGTTs were performed to determine whether the improvements in adiposity and adipocyte morphology associated with chronic ARB translated to an improvement in glucose intolerance. At 2 weeks, mean $\mathrm{AUC}_{\text {glucose }}$ was not different between LETO and OLETF (Fig. 7A and E). At 11 weeks, mean $\mathrm{AUC}_{\text {glucose }}$ was 2.2-fold greater in OLETF compared to LETO, and chronic ARB decreased Printed in Great Britain 
A
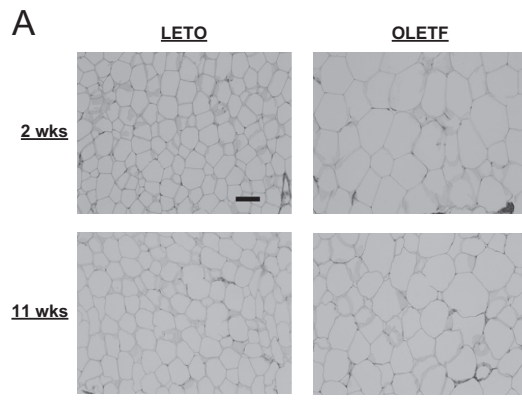

$\square$ LETO
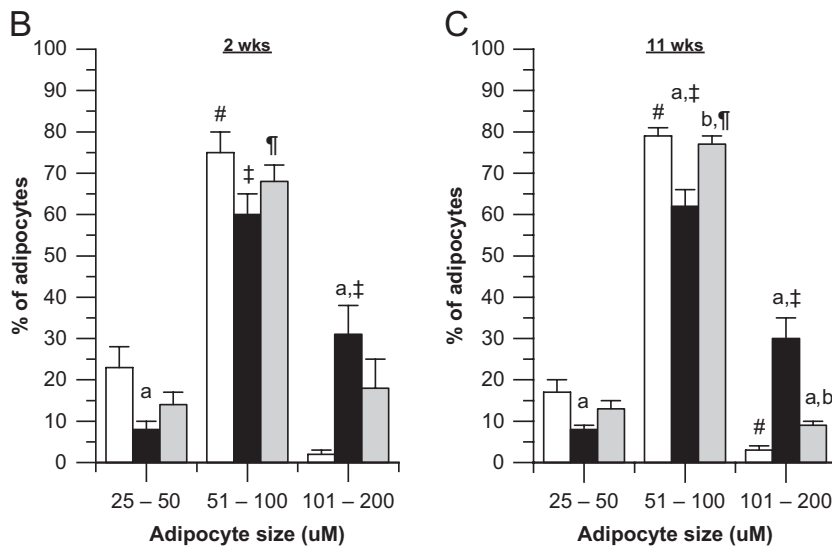

Figure 5

Chronic $\mathrm{AT}_{1}$ blockade decreases the relative abundance of large adipocytes. (A) Representative images of adipocytes from retroperitoneal adipose. Mean ( \pm S.E.) adipocyte size distribution after (B) 2 weeks of treatment in Long-Evans Tokushima Otsuka (LETO; $n=4$ ), Otsuka Long-Evans Tokushima Fatty (OLETF; $n=6)$ and OLETF + ARB $(n=4)$, and (C) after 11 weeks of treatment in LETO $(n=4)$, OLETF $(n=6)$ and OLETF + ARB $(n=5)$. Comparisons were assessed using a two-factor ANOVA at the two time points with group as a between-subjects factor and adipocyte size as a within-subjects factor. ${ }^{a} P<0.05$ vs LETO; ${ }^{b} P<0.05$ vs OLETF; $\# P<0.05$ vs small adipocytes $(25-50 \mu \mathrm{m})$ for LETO; ${ }^{\ddagger} P<0.05$ vs small adipocytes for OLETF; $\Pi P<0.05$ vs small adipocytes for OLETF + ARB. Scale bar: $100 \mu \mathrm{m}$.

it 36\% (Fig. $7 \mathrm{C}$ and $\mathrm{E}$ ). At 2 weeks, mean $\mathrm{AUC}_{\text {insulin }}$ was not different among the groups (Fig. 7B and F). At 11 weeks, mean $\mathrm{AUC}_{\text {insulin }}$ was not different between LETO and OLETF; nevertheless, ARB reduced it $72 \%$ compared to OLETF (Fig. 7B, D and F). These data suggest that chronic $\mathrm{AT}_{1}$ blockade protects against the progression of glucose intolerance in OLETF rats but is not sufficient to completely reverse the impairment.

\section{Chronic AT, blockade decreases the NEFA response to an OGTT}

Plasma NEFA were measured during oGTT to assess the effects of improvements in adiposity and adipocyte morphology associated with chronic $\mathrm{AT}_{1}$ blockade on
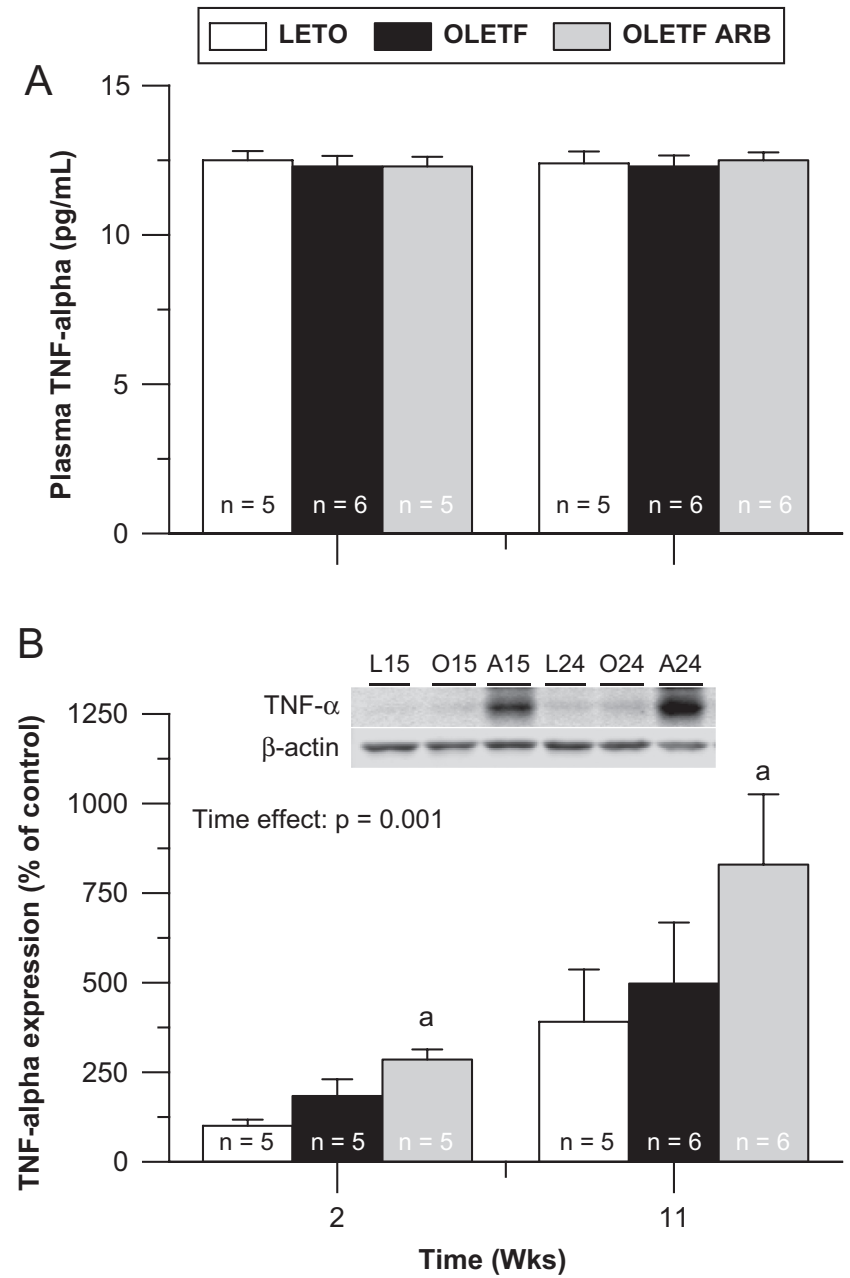

Figure 6

Effects of $A T_{1}$ blockade on systemic and local TNF- $\alpha$. Mean ( \pm S.E.) (A) plasma TNF- $\alpha$ and (B) epididymal fat transmembrane TNF- $\alpha$ (\% change from LETO at 2 weeks) and the representative Western blot bands of Long-Evans Tokushima Otsuka (LETO), Otsuka Long-Evans Tokushima Fatty (OLETF) and OLETF+ARB. Comparisons were assessed using a two-factor ANOVA with group and time as between-subject factors. a $P<0.05$ Vs LETO.

lipid metabolism. At 2 weeks, there was no difference in plasma NEFA in response to the glucose challenge between any of the groups (Fig. 8A). At 11 weeks, plasma NEFA was greater at 15,30 and 60 min following the glucose challenge in OLETF compared to LETO, and this effect was reversed in ARB (Fig. 8B). These results demonstrate that the development of insulin resistance in OLETF rats is associated with the inability to suppress NEFA levels in response to glucose administration. Furthermore, chronic, but not acute $\mathrm{AT}_{1}$ blockade normalized NEFA levels in response to a glucose challenge, suggesting that activation of $\mathrm{AT}_{1}$ contributes to impaired lipid metabolism. 

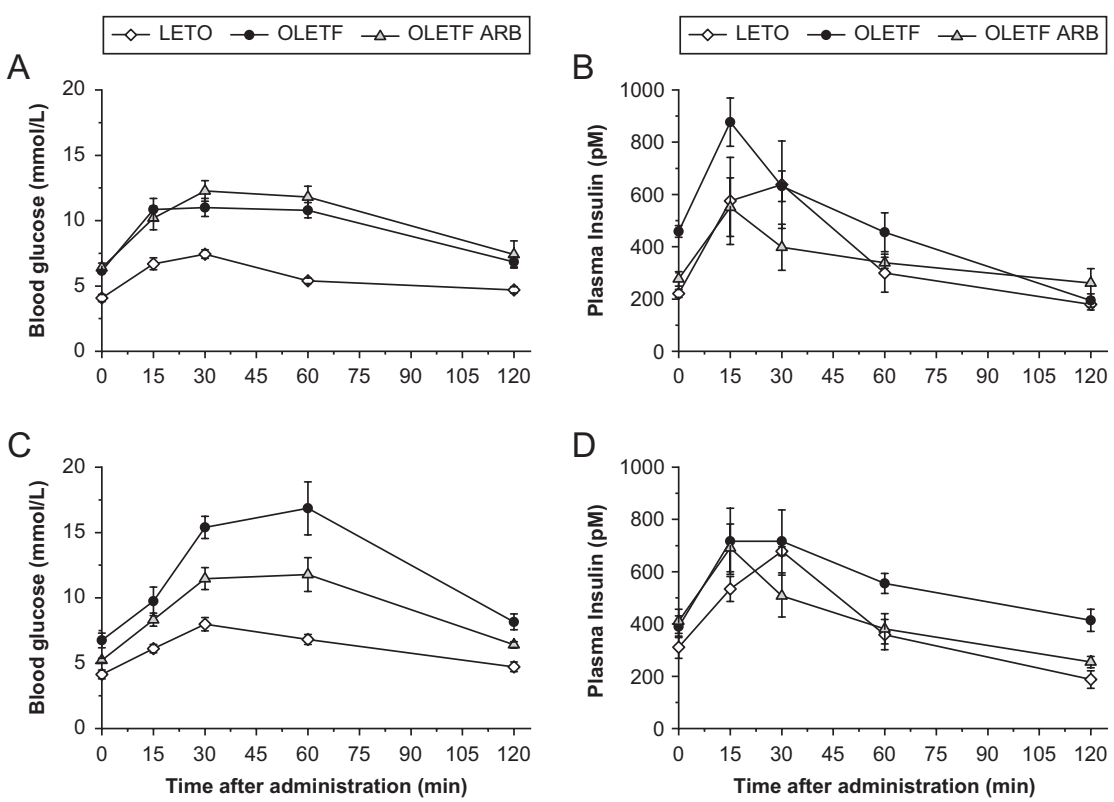

Figure 7

Chronic $\mathrm{AT}_{1}$ blockade attenuates the progression of glucose intolerance. The response of blood glucose and plasma insulin after (A and B,
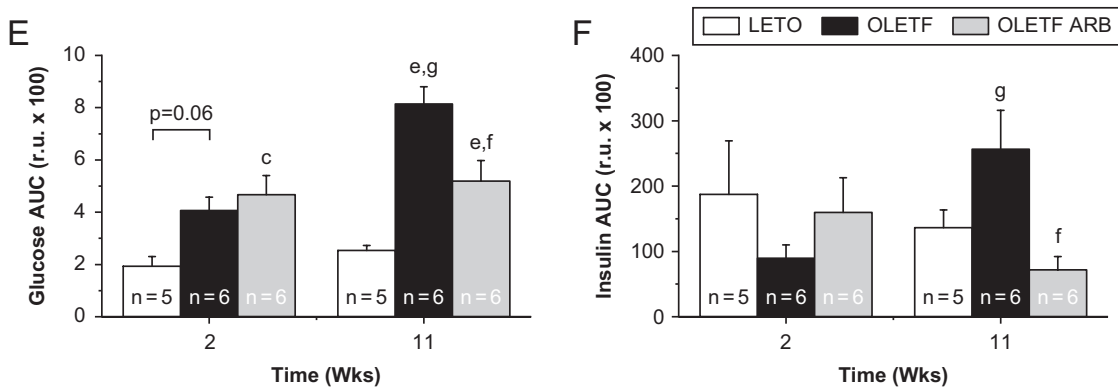
respectively) 2 weeks and ( $C$ and $D$, respectively) 11 weeks of treatment to an oral glucose tolerance test following an overnight fast. The mean ( \pm S.E.) (E) area under the curve for glucose and $(\mathrm{F})$ insulin of Long-Evans Tokushima Otsuka (LETO), Otsuka Long-Evans Tokushima Fatty (OLETF) and OLETF + ARB. Comparisons were assessed using a two-factor ANOVA with group and time as between-subject factors. $c P<0.05$ vs LETO 2 weeks; $P<0.05$ vs LETO 11 weeks; ${ }^{f} P<0.05$ vs OLETF 11 weeks; $9 P<0.05$, OLETF 2 weeks vs OLETF 11 weeks.

\section{Hepatic PEPCK and G6Pase protein expression are not modulated by $\mathrm{AT}_{1}$ signaling in OLETF rats}

Fasting plasma insulin (FPI) along with hepatic proteins involved in insulin signaling and gluconeogenesis was measured to assess the impact of AT1 blockade on hepatic insulin signaling. There was a significant group, but not time effect on FPI and hepatic phosphorylated (p)-insulin receptor (IR):IR ratio. Mean FPI and p-IR:IR ratio were greater in OLETF compared to LETO; however, ARB had no significant effect (Supplementary Fig. 2A and B). There was no group or time effects on the mean expressions of hepatic phosphoenolpyruvate carboxykinase (PEPCK-C) and glucose 6-phosphatase (G6Pase) (Supplementary Fig. 2C and D). Collectively, these results suggest that altered expression of hepatic PEPCK-C and G6Pase may not contribute to the increase in FPG in OLETF rats.

\section{Discussion}

Inappropriately elevated RAS contributes to the dysregulation of glucose homeostasis in part by impairing $\beta$-cell function and peripheral insulin signaling (Favre et al. 2015). Conversely, inhibition of RAS improves $\beta$-cell function and peripheral insulin signaling (Henriksen et al. 2001, Shiuchi et al. 2004, Chu et al. 2006, Wei et al. 2006, Nagai et al. 2009), which can delay the onset of T2DM (Tocci et al. 2011). Nonetheless, it is not clear whether the disease state of the organism and treatment duration determine the beneficial effects of RAS inhibition on pancreatic function and insulin sensitivity. Therefore, the aim of this study was to determine whether acute and chronic $\mathrm{AT}_{1}$ blockade started after the onset of obesity, hyperglycemia and hypertension would have beneficial effects on pancreatic function and peripheral insulin resistance. To this end, the present study demonstrates that regardless of treatment duration, $\mathrm{AT}_{1}$ blockade decreases SBP, BM and fasting plasma TG. Moreover, chronic $\mathrm{AT}_{1}$ blockade was associated with the additional benefits of decreased FPG, AUC $_{\text {glucose }}$, AUC $_{\text {insulin, IRI and }}$ retroperitoneal fat mass and a beneficial shift in adipocyte size. Despite these benefits, chronic $\mathrm{AT}_{1}$ blockade did not have an effect on pancreatic oxidative stress or insulin secretion in our rat model. These results suggest that 


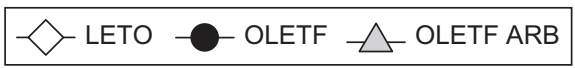

A
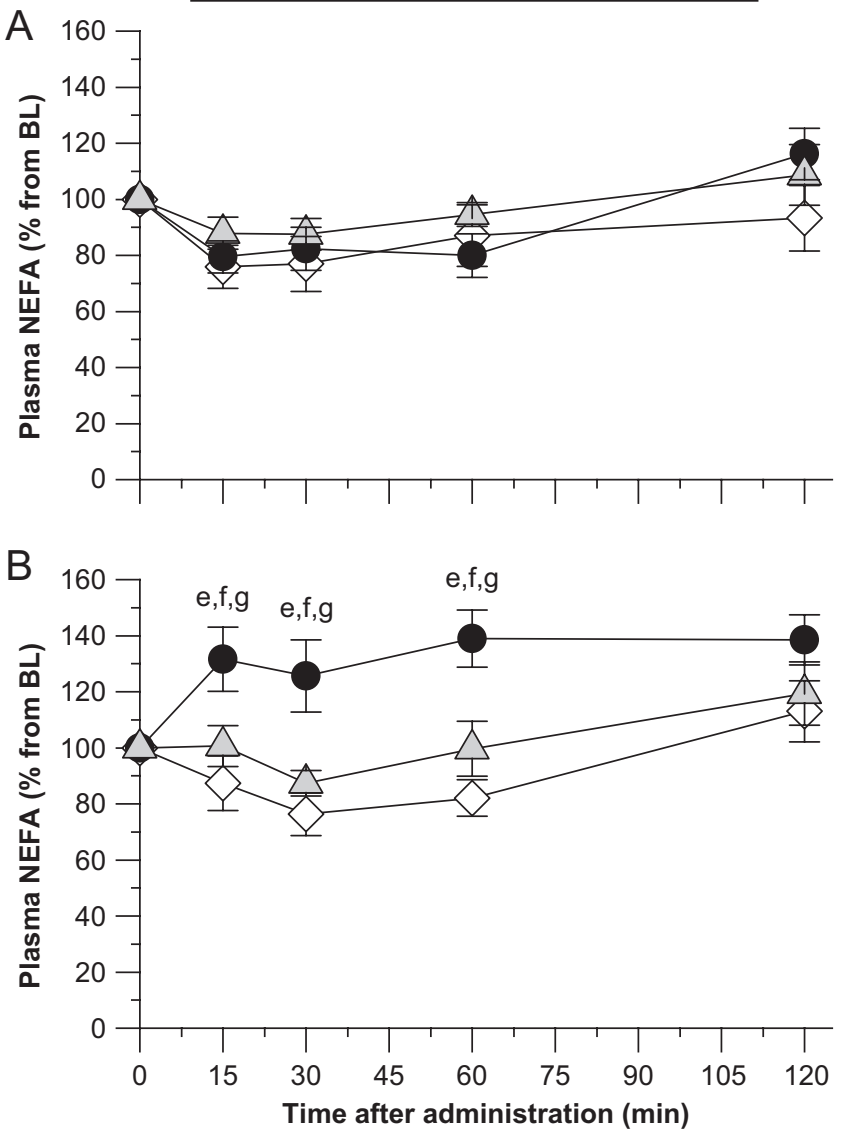

Figure 8

Effects of glucose administration on plasma NEFA. The response of NEFA to an oral glucose tolerance test following an overnight fast (A) after 2 weeks of treatment in Long-Evans Tokushima Otsuka (LETO; $n=5$ ), Otsuka Long-Evans Tokushima Fatty (OLETF; $n=6)$ and OLETF + ARB $(n=6)$, and (B) after 11 weeks of treatment in LETO $(n=5)$, OLETF $(n=6)$, and OLETF+ARB $(n=6)$. Comparisons were assessed using a three-factor ANOVA with group and time (weeks) as between-subject factors and time after administration as a within-subjects factor. $P<0.05$ vs LETO 11 weeks; ${ }^{\text {}} P<0.05$ vs OLETF 11 weeks; $9 P<0.05$, OLETF 2 weeks vs OLETF 11 weeks.

regardless of the disease state, $\mathrm{AT}_{1}$ blockade can improve peripheral insulin resistance but cannot reverse impaired pancreatic function.

We previously demonstrated that 6 weeks of ARB treatment in 9-week old OLETF rats, when the initial detriments of the metabolic syndrome are just appearing in the phenotype, increased insulin secretion associated with a rise in pancreatic GLP-1r protein expression (Rodriguez et al. 2012). An improvement in insulin secretion is one of many avenues by which disruption of RAS can improve glucose intolerance (Chu et al. 2006, Cole et al. 2010). Notwithstanding, in the present study (treatment started at 13 weeks of age), the improvement in glucose tolerance after chronic $\mathrm{AT}_{1}$ blockade was independent of increased insulin secretion. This disparity between the two studies is an important distinction because it may highlight the significance of the timing of treatment on pancreatic function. In support of this view, ACE2 overexpression in 8-week-old $d b / d b$ mice improved glucose tolerance, pancreatic function and prevented $\beta$-cell apoptosis; however, these beneficial effects were not replicated in 16-week-old $d b / d b$ mice (Bindom et al. 2010). Similarly, pioglitazone and/or liraglutide treatment in 7- to 9-week-old $d b / d b$ mice increased $\beta$-cell function and mass, and increased the expression of various genes involved in the regulation of $\beta$-cell function; however, again, these effects were attenuated in 16- to 18-week-old $d b / d b$ mice (Kimura et al. 2015). Collectively, these data suggest that early events that harm the pancreas may be sufficiently detrimental to hinder the ability of targeted treatments to reverse impaired pancreatic function.

Inappropriately elevated Ang II levels result in $\beta$-cell dysfunction in C57BL/6N mice (Lastra et al. 2007, Sauter et al. 2015), and increase the expression and activity of Nox2 in L6 myotubes (Wei et al. 2006). In the pancreas, an increase in oxidant production shifts the oxidant/ antioxidant balance to a pro-oxidant state, leading to an increase in lipid peroxidation since islets have low levels of antioxidant enzymes (Tiedge et al. 1997). 4-HNE, a by-product of lipid peroxidation, decreases islet insulin and DNA content (Suarez-Pinzon et al. 1996). In the present study, pancreatic 4-HNE levels were increased in OLETF rats, and pancreatic SOD, catalase and GPx enzyme activities were decreased. Collectively, these results demonstrate a chronic pro-oxidant state of the pancreas in obese pre-diabetic OLETF rats. Furthermore, these results suggest that the decrease in pancreatic insulin content in OLETF may be a result of the pro-oxidant state of the pancreas. Moreover, OLETF rats also exhibited decreased insulin secretion despite increased insulin levels after 2 weeks of treatment, suggesting that defective glucose sensing may be responsible for this impairment. To this effect, $\beta$-cell glucose toxicity decreases the expression of GLP-1r and GLUT2, leading to impaired insulin secretion (Thorens et al. 1992, Xu et al. 2007, Kawashima et al. 2011). Additionally, 10-week-old, OLETF rats have increased levels of plasma dipeptidyl peptidase-4 activity compared to food-restricted OLETF rats when fed ad libitum (Kirino et al. 2011), which would decrease plasma GLP-1 (Rodriguez et al. 2012). Collectively, these data demonstrate that early in the development of metabolic syndrome, OLETF rats are afflicted by an increased prooxidant state in the pancreas and decreased plasma GLP-1, 
leading to an impairment in GSIS. It is important to note that while acute or chronic $\mathrm{AT}_{1}$ blockade cannot reverse these detriments, RAS inhibition before the onset of dysregulated insulin secretion is protective (Nakayama et al. 2005, Rodriguez et al. 2012, Zhang et al. 2013), suggesting that these detriments are irreversible without sufficiently early intervention. If so, identifying appropriate targets for improving therapies to reverse dysregulated pancreatic function associated with the manifestation of metabolic syndrome will be especially necessary.

Obesity inappropriately activates RAS in animal models and humans (Boustany et al. 2004, Engeli et al. 2005). RAS inhibition decreases BM and visceral fat mass in animal models of metabolic syndrome (Benson et al. 2004, Miesel et al. 2012, Müller-Fielitz et al. 2012, 2014, 2015). These beneficial effects on BM and visceral fat mass are partially mediated by Mas receptor activation (Schuchard et al. 2015) and are attributed to multiple factors including the prevention of leptin resistance (Müller-Fielitz et al. 2014, 2015) and increased circulating levels of adiponectin (Zorad et al. 2006, Weisinger et al. 2009). In the present study, we did not observe a reduction in $\mathrm{BM}$ regardless of treatment duration; nevertheless, ARB treatment blunted BM gain during the treatment period. The difference in our findings may be attributed to the diets used in the aforementioned studies, which were higher in carbohydrates and fat as compared to the standard chow used in our study. Likewise, 4 weeks of telmisartan treatment did not reduce BM in spontaneously hypertensive (SHR) rats fed a standard chow (Li et al. 2006). Moreover, the BM reducing effects of ARB are dependent on the ARB dose and intact leptin signaling, with higher doses decreasing food intake and BM when leptin signaling is normal (Müller-Fielitz et al. 2011). Although OLETF rats have intact leptin signaling at 5 weeks of age, by 8 weeks of age, they develop peripheral but not central leptin resistance (Niimi et al. 1999), which may be a result of an acquired impairment in the transport of leptin across the blood-brain barrier (Banks et al. 2003). While $\mathrm{AT}_{1}$ blockade regardless of treatment duration did not decrease $\mathrm{BM}$, we found that chronic $\mathrm{AT}_{1}$ blockade decreased retro fat mass and the relative abundance of large adipocytes and normalized the relative abundance of medium adipocytes indicative of a beneficial shift in adipose morphology. Nevertheless, acute $\mathrm{AT}_{1}$ blockade had no detectable effect on adipocyte morphology, glucose intolerance or FPG, suggesting that: (1) at this stage in the development of metabolic syndrome, other factors beyond $\mathrm{AT}_{1}$ activation contribute to a greater extent or (2) at this stage of the condition, acute disruption of RAS is insufficient to overcome the progression of the metabolic syndrome. Although we only observed an improvement in adipocyte morphology after chronic $\mathrm{AT}_{1}$ blockade, previous studies have shown similar results regardless of treatment duration (Furuhashi et al. 2004, Mori et al. 2007, Tomono et al. 2008, Muñoz et al. 2009, Nagai et al. 2009, Iwai et al. 2010, Müller-Fielitz et al. 2012). This discrepancy may be due to the use of different animal models and/or RAS inhibitor, or the time frame of treatment necessary to detect an effect.

Adipose expansion as seen in obesity is mediated by adipocyte hypertrophy, hyperplasia or both. Similarly, the detrimental effects of obesity on metabolic and cardiovascular health are associated with a higher abundance of hypertrophic adipocytes (Choe et al. 2016). These large adipocytes have lower GLUT4 translocation in response to insulin (Franck et al. 2007), higher lipolysis rates (Laurencikiene et al. 2011) and higher proinflammatory adipokine expression and secretion (Skurk et al. 2007). Therefore, large adipocytes are associated with the development of insulin resistance and type 2 diabetes (Acosta et al. 2015, Kim et al. 2015). In the present study, chronic $\mathrm{AT}_{1}$ blockade decreased the relative abundance of large adipocytes. This positive shift in adipocyte morphology may partially explain the improvement in glucose homeostasis. Recent evidence shows that these effects are independent of the blood pressure lowering effects of $\mathrm{AT}_{1}$ blockade (Müller-Fielitz et al. 2014). However, the improvement in glucose homeostasis may be independent of increased glucose uptake into adipocytes as adipose itself makes a minor contribution to glucose disposal in response to feeding (Baron et al. 1988). In support of this view, a previous study found that glucose uptake in adipocytes was not altered by telmisartan treatment in Sprague Dawley rats or transgenic rats with low brain angiotensinogen fed a cafeteria diet (Winkler et al. 2016). Collectively, these results suggest that the improvement in glucose homeostasis may be the result of other factors associated with a positive shift in adipocyte morphology such as increased expression and secretion of anti-inflammatory adipokines and decreased expression and secretion of pro-inflammatory adipokines (Skurk et al. 2007). In the present study, OLETF rats did not show increased systemic or local inflammation. Additionally, adiponectin levels decreased with time, which may be a result of increased $\mathrm{BM}$ as obesity is associated with decreased circulating levels of adiponectin (Arita et al. 1999). This is significant because adiponectin is important for increasing peripheral insulin sensitivity (Yamauchi 
et al. 2001), suggesting that the observed improvement in glucose homeostasis after chronic $\mathrm{AT}_{1}$ blockade is not mediated by adiponectin. In the same way, a previous study found that $\mathrm{AT}_{1}$ blockade improves glucose homeostasis in SHR rats and that these effects are not mediated by peroxisome proliferator-activated receptor (PPAR)- $\gamma$ (Müller-Fielitz et al. 2012), a transcriptional regulator of adiponectin (Iwaki et al. 2003). Furthermore, we found that at 11 weeks, a glucose challenge did not suppress circulating NEFA levels and that chronic $\mathrm{AT}_{1}$ blockade reversed this impairment, suggesting that the improvement in glucose homeostasis may result from increased adipogenesis, decreased lipolysis or both, in smaller insulin-sensitive adipocytes (Laforest et al. 2015). Previous studies have demonstrated that Ang II inhibits lypolysis (Goossens et al. 2006); however, a different study demonstrated that in individuals with impaired glycemia, valsartan treatment for 26 weeks suppressed postprandial free fatty acids (Moors et al. 2013), suggesting a suppression of lipolysis. Furthermore, a study in primary cultured human preadipocytes demonstrated that $\mathrm{AT}_{1}$ blockade increased the lipid accumulation and differentiation of these cells (Janke et al. 2002). Collectively, these results suggest that $\mathrm{AT}_{1}$ blockade may protect against ectopic lipid deposition in skeletal muscle by suppressing lipolysis and increasing preadipocyte differentiation, leading to an improvement in insulin sensitivity and ultimately on glycemia (Sharma et al. 2002). Nonetheless, we cannot rule out that other mechanisms such as blunting of the hypothalamic pituitary axis activity in response to stress may contribute to the $\mathrm{AT}_{1}$-associated improvements in glucose homeostasis (Armando et al. 2001, Miesel et al. 2012).

\section{Conclusion}

In summary, the present study demonstrates that after the onset of obesity, hyperglycemia and hypertension in OLETF rats, chronic $\mathrm{AT}_{1}$ blockade results in a beneficial shift in adipocyte morphology, and improved FPG and glucose intolerance regardless of the glycemic state at the onset of the treatment. Despite this, $\mathrm{AT}_{1}$ blockade cannot reverse impaired insulin secretion, suggesting that once the pancreas has been compromised, recovery will be particularly challenging, and the severity of the condition may be masked by the apparent improvement in systemic glucose tolerance. Should these findings in a rat model recapitulate in humans, early RAS inhibition may be crucial to preserving pancreatic function, and identifying the other factors that contribute to the defined impairments in pancreatic function will be critical for proper management of metabolic syndrome especially as it relates to the timing of treatment.

\section{Supplementary data}

This is linked to the online version of the paper at https://doi.org/10.1530/ JOE-17-0678.

\section{Declaration of Interest}

The authors declare that there is no conflict of interest that could be perceived as prejudicing the impartiality of the research reported.

\section{Funding}

R Rodriguez was supported by NIH NCMHD 9T37MD001480 and by a Faculty Mentor Program Fellowship from the University of California Merced Graduate Division. J N Minas was supported by NIH NCMHD 9T37MD001480. R M Ortiz was partially supported by NIH NHLBIK02HL103787. Research was partially funded by NIH NHLBIR01HL091767.

\section{Author contribution statement}

R R, J P V-M, D N, A N and R M O designed the research. R R and J N M performed the animal experiments and analyzed the samples and data. $R$ R, J P V-M, D G P, S H A and R M O interpreted the results. R R wrote the original draft of the manuscript. R R, J P V-M, D N, D G P, A N and R M O edited and revised the manuscript. All authors approved the final version of the manuscript for submission.

\section{Acknowledgments}

We would like to thank Dr N Pelisch, Dr K Kitada, A Lee, M Thorwald, P Montez, M Moreno and J Aguil for their assistance during dissections and with laboratory analyses. We also thank Dr J A Viscarra, Dr H Brooks and Dr $\mathrm{S} \mathrm{H}$ Adams for their comments on a draft of the manuscript. Finally, we are grateful to Drs J Choi, M Kitazawa, N Oviedo and Dr S H Adams for their discussion of the results. Olmesartan was kindly donated by Daiichi-Sankyo (Tokyo, Japan) to A Nishiyama.

\section{References}

Acosta JR, Douagi I, Andersson DP, Bäckdahl J, Rydén M, Arner P \& Laurencikiene J 2015 Increased fat cell size: a major phenotype of subcutaneous white adipose tissue in non-obese individuals with type 2 diabetes. Diabetologia 59 560-570. (https://doi.org/10.1007/s00125015-3810-6)

Allison DB, Paultre F, Maggio C, Mezzitis N \& Pi-Sunyer FX 1995 The use of areas under curves in diabetes research. Diabetes Care 18 245-250. (https://doi.org/10.2337/diacare.18.2.245)

Arita Y, Kihara S, Ouchi N, Takahashi M, Maeda K, Miyagawa J-I, Hotta K, Shimomura I, Nakamura T, Miyaoka K, et al. 1999 Paradoxical decrease of an adipose-specific protein, adiponectin, in obesity. 
Biochemical and Biophysical Research Communications 257 79-83. (https://doi.org/10.1006/bbrc.1999.0255)

Armando I, Carranza A, Nishimura Y, Hoe K-L, Barontini M, Terrón JA, Falcón-Neri A, Ito T, Juorio AV \& Saavedra JM 2001 Peripheral administration of an angiotensin II at1 receptor antagonist decreases the hypothalamic-pituitary-adrenal response to isolation stress. Endocrinology 142 3880-3889. (https://doi.org/10.1210/ endo.142.9.8366)

Banks WA \& Farrell CL 2003 Impaired transport of leptin across the blood-brain barrier in obesity is acquired and reversible. American Journal of Physiology: Endocrinology and Metabolism 285 E10-E15. (https://doi.org/10.1152/ajpendo.00468.2002)

Baron AD, Brechtel G, Wallace P \& Edelman SV 1988 Rates and tissue sites of non-insulin- and insulin-mediated glucose uptake in humans. American Journal of Physiology: Endocrinology and Metabolism 255 E769-E774. (https://doi.org/10.1152/ajpendo.1988.255.6.E769)

Benson SC, Pershadsingh HA, Ho CI, Chittiboyina A, Desai P, Pravenec M, Qi N, Wang J, Avery MA \& Kurtz TW 2004 Identification of telmisartan as a unique angiotensin II receptor antagonist with selective ppar $\gamma$-modulating activity. Hypertension 43 993-1002. (https://doi.org/10.1161/01.HYP.0000123072.34629.57)

Bindom SM, Hans CP, Xia H, Boulares HA \& Lazartigues E 2010 Angiotensin i-converting enzyme type 2 (ace2) gene therapy improves glycemic control in diabetic mice. Diabetes 59 2540-2548. (https://doi.org/10.2337/db09-0782)

Bosch J, Yusuf S, Gerstein HC, Pogue J, Sheridan P, Dagenais G, Diaz R, Avezum A, Lanas F, Probstfield J, et al. 2006 Effect of ramipril on the incidence of diabetes. New England Journal of Medicine 355 1551-1562. (https://doi.org/10.1056/NEJMoa065061)

Boustany CM, Bharadwaj K, Daugherty A, Brown DR, Randall DC \& Cassis LA 2004 Activation of the systemic and adipose reninangiotensin system in rats with diet-induced obesity and hypertension. American Journal of Physiology: Regulatory, Integrative and Comparative Physiology 287 R943-R949. (https://doi.org/10.1152/ ajpregu.00265.2004)

Chhabra K, Xia H, Pedersen K, Speth R \& Lazartigues E 2013 Pancreatic angiotensin-converting enzyme 2 improves glycemia in angiotensin II-infused mice. American Journal of Physiology: Endocrinology and Metabolism 304 E874-E884. (https://doi.org/10.1152/ ajpendo.00490.2012)

Choe SS, Huh JY, Hwang IJ, Kim JI \& Kim JB 2016 Adipose tissue remodeling: its role in energy metabolism and metabolic disorders. Frontiers in Endocrinology 7 30. (https://doi.org/10.3389/ fendo.2016.00030)

Chu KY \& Leung PS 2007 angiotensin II type 1 receptor antagonism mediates uncoupling protein 2-driven oxidative stress and ameliorates pancreatic islet $\beta$-cell function in young type 2 diabetic mice. Antioxidants and Redox Signaling 9 869-878. (https://doi.org/10.1089/ ars.2007.1590)

Chu KY, Lau T, Carlsson P-O \& Leung PS 2006 angiotensin II type 1 receptor blockade improves $\beta$-cell function and glucose tolerance in a mouse model of type 2 diabetes. Diabetes 55 367-374. (https://doi. org/10.2337/diabetes.55.02.06.db05-1022)

Cole BK, Keller SR, Wu R, Carter JD, Nadler JL \& Nunemaker CS 2010 Valsartan protects pancreatic islets and adipose tissue from the inflammatory and metabolic consequences of a high-fat diet in mice. Hypertension 55 715-721. (https://doi.org/10.1161/ HYPERTENSIONAHA.109.148049)

Csibi A, Communi D, Müller N \& Bottari SP 2010 angiotensin II inhibits insulin-stimulated glut4 translocation and akt activation through tyrosine nitration-dependent mechanisms. PLOS ONE 5 e10070. (https://doi.org/10.1371/journal.pone.0010070)

Engeli S, Böhnke J, Gorzelniak K, Janke J, Schling P, Bader M, Luft FC \& Sharma AM 2005 Weight loss and the renin-angiotensin-aldosterone system. Hypertension 45 356-362. (https://doi.org/10.1161/01. HYP.0000154361.47683.d3)
Favre GA, Esnault VLM \& Van Obberghen E 2015 Modulation of glucose metabolism by the renin-angiotensin-aldosterone system. American Journal of Physiology: Endocrinology and Metabolism 308 E435-E449. (https://doi.org/10.1152/ajpendo.00391.2014)

Flegal KM, Kruszon-Moran D, Carroll MD, Fryar CD \& Ogden CL 2016 Trends in obesity among adults in the United States, 2005 to 2014. JAMA 315 2284-2291. (https://doi.org/10.1001/jama.2016.6458)

Franck N, Stenkula KG, Öst A, Lindström T, Strålfors P \& Nystrom FH 2007 Insulin-induced glut 4 translocation to the plasma membrane is blunted in large compared with small primary fat cells isolated from the same individual. Diabetologia 50 1716-1722. (https://doi. org/10.1007/s00125-007-0713-1)

Furuhashi M, Ura N, Takizawa H, Yoshida D, Moniwa N, Murakami H, Higashiura K \& Shimamoto K 2004 Blockade of the renin-angiotensin system decreases adipocyte size with improvement in insulin sensitivity. Journal of Hypertension 22 1977-1982. (https://doi. org/10.1097/00004872-200410000-00021)

Gaal LF, Mertens IL \& Block CE 2006 Mechanisms linking obesity with cardiovascular disease. Nature 444 875-880. (https://doi.org/10.1038/ nature05487)

Goossens GH, Blaak EE, Arner P, Saris WHM \& Baak MAV 2006 angiotensin II: a hormone that affects lipid metabolism in adipose tissue. International Journal of Obesity 31 382-384. (https:// doi:10.1038/sj.ijo.0803388)

Habibi J, Whaley-Connell A, Hayden MR, DeMarco VG, Schneider R, Sowers SD, Karuparthi P, Ferrario CM \& Sowers JR 2008 Renin inhibition attenuates insulin resistance, oxidative stress, and pancreatic remodeling in the transgenic ren2 rat. Endocrinology 149 5643-5653. (https://doi.org/10.1210/en.2008-0070)

Henriksen EJ, Jacob S, Kinnick TR, Teachey MK \& Krekler M 2001 Selective angiotensin II receptor antagonism reduces insulin resistance in obese zucker rats. Hypertension 38 884-890. (https://doi. org/10.1161/hy1101.092970)

Iwai M, Kanno H, Tomono Y, Inaba S, Senba I, Furuno M, Mogi M \& Horiuchi M 2010 Direct renin inhibition improved insulin resistance and adipose tissue dysfunction in type 2 diabetic kk-a(y) mice. Journal of Hypertension 28 1471-1481. (https://doi.org/10.1097/ HJH.Ob013e32833bc420)

Iwaki M, Matsuda M, Maeda N, Funahashi T, Matsuzawa Y, Makishima M \& Shimomura I 2003 Induction of adiponectin, a fat-derived antidiabetic and antiatherogenic factor, by nuclear receptors. Diabetes 52 1655-1663. (https://doi.org/10.2337/diabetes.52.7.1655)

Janke J, Engeli S, Gorzelniak K, Luft FC \& Sharma AM 2002 Mature adipocytes inhibit in vitro differentiation of human preadipocytes via angiotensin type 1 receptors. Diabetes 51 1699-1707. (https://doi. org/10.2337/diabetes.51.6.1699)

Kahn SE, Hull RL \& Utzschneider KM 2006 Mechanisms linking obesity to insulin resistance and type 2 diabetes. Nature $\mathbf{4 4 4} 840-846$. (https://doi.org/10.1038/nature05482)

Kawano K, Hirashima T, Mori S, Saitoh Y, Kurosumi M \& Natori T 1992 Spontaneous long-term hyperglycemic rat with diabetic complications. Otsuka long-evans tokushima fatty (oletf) strain. Diabetes 41 1422-1428. (https://doi.org/10.2337/diab.41.11.1422)

Kawashima S, Matsuoka T-AA, Kaneto H, Tochino Y, Kato K, Yamamoto K, Yamamoto T, Matsuhisa M \& Shimomura I 2011 Effect of alogliptin, pioglitazone and glargine on pancreatic $\beta$-cells in diabetic $\mathrm{db} / \mathrm{db}$ mice. Biochemical and Biophysical Research Communications 404 534-540. (https://doi.org/10.1016/j.bbrc.2010.12.021)

Kim J, Huh J, Sohn J, Choe S, Lee Y, Lim C, Jo A, Park S, Han W \& Kim J 2015 Lipid-overloaded enlarged adipocytes provoke insulin resistance independent of inflammation. Molecular and Cellular Biology 35 1686-1699. (https://doi.org/10.1128/MCB.01321-14)

Kimura T, Kaneto H, Shimoda M, Hirukawa H, Okauchi S, Kohara K, Hamamoto S, Tawaramoto K, Hashiramoto M \& Kaku K 2015 Protective effects of pioglitazone and/or liraglutide on pancreatic $\beta$-cells in $\mathrm{db} / \mathrm{db}$ mice: comparison of their effects between in an early 
and advanced stage of diabetes. Molecular and Cellular Endocrinology 400 78-89. (https://doi.org/10.1016/j.mce.2014.11.018)

Kirino Y, Sato Y, Kamimoto T, Kawazoe K \& Minakuchi K 2011 Altered dipeptidyl peptidase- 4 activity during the progression of hyperinsulinemic obesity and islet atrophy in spontaneously latestage type 2 diabetic rats. American Journal of Physiology: Endocrinology and Metabolism 300 E372-E379. (https://doi.org/10.1152/ ajpendo.00319.2010)

Laforest S, Labrecque J, Michaud A, Cianflone K \& Tchernof A 2015 Adipocyte size as a determinant of metabolic disease and adipose tissue dysfunction. Critical Reviews in Clinical Laboratory Sciences 52 301-313. (https://doi.org/10.3109/10408363.2015.1041582)

Lastra G \& Manrique C 2007 The expanding role of oxidative stress, renin angiotensin system, and $\beta$-cell dysfunction in the cardiometabolic syndrome and type 2 diabetes mellitus. Antioxidants and Redox Signaling 9 943-954. (https://doi.org/10.1089/ars.2007.1615)

Laurencikiene J, Skurk T, Kulyté A, Hedén P, Åström G, Sjölin E, Rydén M, Hauner H \& Arner P 2011 Regulation of lipolysis in small and large fat cells of the same subject. Journal of Clinical Endocrinology and Metabolism 96 E2045-E2049. (https://doi.org/10.1210/jc.2011-1702)

Li Y-Q, Ji H, Zhang Y-H, Ding D-Y \& Ye X-L 2006 Metabolic effects of telmisartan in spontaneously hypertensive rats. Naunyn-Schmiedeberg's Archives of Pharmacology 373 264-270. (https://doi.org/10.1007/ s00210-006-0069-y)

Li N, Li B, Brun T, Deffert-Delbouille C, Mahiout Z, Daali Y, Ma X-J, Krause K-H \& Maechler P 2012 Nadph oxidase nox2 defines a new antagonistic role for reactive oxygen species and camp/pka in the regulation of insulin secretion. Diabetes 61 2842-2850. (https://doi. org/10.2337/db12-0009)

Maki KC, McKenney JM, Farmer MV, Reeves MS \& Dicklin MR 2009 Indices of insulin sensitivity and secretion from a standard liquid meal test in subjects with type 2 diabetes, impaired or normal fasting glucose. Nutrition Journal 8 22. (https://doi.org/10.1186/1475-28918-22)

McMurray JJ, Holman RR, Haffner SM, Bethel MA, Holzhauer B, Hua TA, Belenkov Y, Boolell M, Buse JB, Buckley BM, et al. 2010 Effect of valsartan on the incidence of diabetes and cardiovascular events. New England Journal of Medicine 362 1477-1490. (https://doi.org/10.1056/ NEJMoa1001121)

Miesel A, Müller-Fielitz H, Jöhren O, Vogt FM \& Raasch W 2012 Double blockade of angiotensin II (at1)-receptors and ace does not improve weight gain and glucose homeostasis better than single-drug treatments in obese rats. British Journal of Pharmacology 165 2721-2735. (https://doi.org/10.1111/j.1476-5381.2011.01726.x)

Montez P, Vázquez-Medina JP, Rodríguez R, Thorwald MA, Viscarra JA, Lam L, Peti-Peterdi J, Nakano D, Nishiyama A \& Ortiz RM 2012 Angiotensin receptor blockade recovers hepatic ucp 2 expression and aconitase and sdh activities and ameliorates hepatic oxidative damage in insulin resistant rats. Endocrinology 153 5746-5759. (https://doi. org/10.1210/en.2012-1390)

Moors CCM, Blaak EE, van der Zijl NJ, Diamant M \& Goossens GH 2013 The effects of long-term valsartan treatment on skeletal muscle fatty acid handling in humans with impaired glucose metabolism. Journal of Clinical Endocrinology and Metabolism 98 E891-E896. (https://doi. org/10.1210/jc.2012-4067)

Mori Y, Itoh Y \& Tajima N 2007 angiotensin II receptor blockers downsize adipocytes in spontaneously type 2 diabetic rats with visceral fat obesity. American Journal of Hypertension 20 431-436. (https://doi. org/10.1016/j.amjhyper.2006.09.016)

Müller-Fielitz H, Markert A, Wittmershaus C, Pahlke F, Jöhren O \& Raasch W 2011 Weight loss and hypophagia after high-dose at1blockade is only observed after high dosing and depends on regular leptin signalling but not blood pressure. Naunyn-Schmiedeberg's Archives of Pharmacology 383 373-384. (https://doi.org/10.1007/ s00210-011-0602-5)
Müller-Fielitz H, Landolt J, Heidbreder M, Werth S, Vogt FM, Jöhren O \& Raasch W 2012 Improved insulin sensitivity after long-term treatment with at 1 blockers is not associated with ppary target gene regulation. Endocrinology 153 1103-1115. (https://doi.org/10.1210/en.2011-0183)

Müller-Fielitz H, Hübel N, Mildner M, Vogt FM, Barkhausen J \& Raasch W 2014 Chronic blockade of angiotensin at 1 receptors improves cardinal symptoms of metabolic syndrome in diet-induced obesity in rats. British Journal of Pharmacology 171 746-760. (https://doi.org/10.1111/ bph.12510)

Müller-Fielitz H, Lau M, Geißler C, Werner L, Winkler M \& Raasch W 2015 Preventing leptin resistance by blocking angiotensin II at1 receptors in diet-induced obese rats. British Journal of Pharmacology 172 857-868. (https://doi.org/10.1111/bph.12949)

Muñoz MC, Giani JF, Dominici FP, Turyn D \& Toblli JE 2009 Longterm treatment with an angiotensin II receptor blocker decreases adipocyte size and improves insulin signaling in obese zucker rats. Journal of Hypertension 27 2409-2420. (https://doi.org/10.1097/ HJH.0b013e3283310e1b)

Nagai Y, Ichihara A, Nakano D, Kimura S, Pelisch N, Fujisawa Y, Hitomi H, Hosomi N, Kiyomoto H, Kohno M, et al. 2009 Possible contribution of the non-proteolytic activation of prorenin to the development of insulin resistance in fructose-fed rats. Experimental Physiology 94 1016-1023. (https://doi.org/10.1113/expphysiol.2009.048108)

Nakayama M, Inoguchi T, Sonta T, Maeda Y, Sasaki S, Sawada F, Tsubouchi H, Sonoda N, Kobayashi K, Sumimoto H, et al. 2005 Increased expression of nad(p)h oxidase in islets of animal models of type 2 diabetes and its improvement by an at 1 receptor antagonist. Biochemical and Biophysical Research Communications 332 927-933. (https://doi.org/10.1016/j.bbrc.2005.05.065)

Niimi M, Sato M, Yokote R, Tada S \& Takahara J 1999 Effects of central and peripheral injection of leptin on food intake and on brain fos expression in the otsuka long-evans tokushima fatty rat with hyperleptinaemia. Journal of Neuroendocrinology 11 605-611. (https:// doi.org/10.1046/j.1365-2826.1999.00368.x)

Nishiyama A, Nakagawa T, Kobori H, Nagai Y, Okada N, Konishi Y, Morikawa T, Okumura M, Meda I, Kiyomoto H, et al. 2008 Strict angiotensin blockade prevents the augmentation of intrarenal angiotensin II and podocyte abnormalities in type 2 diabetic rats with microalbuminuria. Journal of Hypertension 26 1849-1859. (https://doi. org/10.1097/HJH.0b013e3283060efa)

Rao RH 1996 Pressor doses of angiotensin II increase hepatic glucose output and decrease insulin sensitivity in rats. Journal of Endocrinology 148 311-318. (https://doi.org/10.1677/joe.0.1480311)

Retnakaran R, Shen S, Hanley AJ, Vuksan V, Hamilton JK \& Zinman B 2008 Hyperbolic relationship between insulin secretion and sensitivity on oral glucose tolerance test. Obesity 16 1901-1907. (https://doi.org/10.1038/oby.2008.307)

Rodriguez R, Viscarra JA, Minas JN, Nakano D, Nishiyama A \& Ortiz RM 2012 Angiotensin receptor blockade increases pancreatic insulin secretion and decreases glucose intolerance during glucose supplementation in a model of metabolic syndrome. Endocrinology 153 1684-1695. (https://doi.org/10.1210/en.2011-1885)

Sauter NS, Thienel C, Plutino Y, Kampe K, Dror E, Traub S, Timper K, Bédat B, Pattou F, Kerr-Conte J, et al. 2015 angiotensin II induces interleukin-1 $\beta$-mediated islet inflammation and $\beta$-cell dysfunction independently of vasoconstrictive effects. Diabetes 64 1273-1283. (https://doi.org/10.2337/db14-1282)

Schuchard J, Winkler M, Stölting I, Schuster F, Vogt FM, Barkhausen J, Thorns C, Santos RA, Bader M \& Raasch W 2015 Lack of weight gain after angiotensin at 1 receptor blockade in diet-induced obesity is partly mediated by an angiotensin-(1-7)/mas-dependent pathway. British Journal of Pharmacology 172 3764-3778. (https://doi org/10.1111/bph.13172)

Sharma AM, Janke J, Gorzelniak K, Engeli S \& Luft FC 2002 Angiotensin blockade prevents type 2 diabetes by formation of 
fat cells. Hypertension 40 609-611. (https://doi.org/10.1161/01. HYP.0000036448.44066.53)

Shiuchi T, Iwai M, Li H-SS, Wu L, Min L-JJ, Li J-MM, Okumura M, Cui T-XX \& Horiuchi M 2004 angiotensin II type-1 receptor blocker valsartan enhances insulin sensitivity in skeletal muscles of diabetic mice. Hypertension 43 1003-1010. (https://doi.org/10.1161/01. HYP.0000125142.41703.64)

Skurk T, Alberti-Huber C, Herder C \& Hauner H 2007 Relationship between adipocyte size and adipokine expression and secretion. Journal of Clinical Endocrinology and Metabolism 92 1023-1033. (https://doi.org/10.1210/jc.2006-1055)

Suarez-Pinzon WL, Strynadka K \& Rabinovitch A 1996 Destruction of rat pancreatic islet beta-cells by cytokines involves the production of cytotoxic aldehydes. Endocrinology 137 5290-5296. (https://doi. org/10.1210/endo.137.12.8940348)

Thorens B, Wu YJ, Leahy JL \& Weir GC 1992 The loss of glut2 expression by glucose-unresponsive beta cells of $\mathrm{db} / \mathrm{db}$ mice is reversible and is induced by the diabetic environment. Journal of Clinical Investigation 90 77-85. (https://doi.org/10.1172/JCI115858)

Tiedge M, Lortz S, Drinkgern J \& Lenzen S 1997 Relation between antioxidant enzyme gene expression and antioxidative defense status of insulin-producing cells. Diabetes 46 1733-1742. (https://doi. org/10.2337/diab.46.11.1733)

Tocci G, Paneni F, Palano F, Sciarretta S, Ferrucci A, Kurtz T, Mancia G \& Volpe M 2011 Angiotensin-converting enzyme inhibitors, angiotensin II receptor blockers and diabetes: a meta-analysis of placebocontrolled clinical trials. American Journal of Hypertension 24 582-590. (https://doi.org/10.1038/ajh.2011.8)

Tomono Y, Iwai M, Inaba S, Mogi M \& Horiuchi M 2008 Blockade of at1 receptor improves adipocyte differentiation in atherosclerotic and diabetic models. American Journal of Hypertension 21 206-212. (https:// doi.org/10.1038/ajh.2007.50)

Viscarra JA, Champagne CD, Crocker DE \& Ortiz RM 2011 5'ampactivated protein kinase activity is increased in adipose tissue of northern elephant seal pups during prolonged fasting-induced insulin resistance. Journal of Endocrinology 209 317-325. (https://doi. org/10.1530/JOE-11-0017)

Wei Y, Sowers JR, Nistala R, Gong H, Uptergrove GME, Clark SE Morris EM, Szary N, Manrique C \& Stump CS 2006 angiotensin
II-induced nadph oxidase activation impairs insulin signaling in skeletal muscle cells. Journal of Biological Chemistry 281 35137-35146. (https://doi.org/10.1074/jbc.M601320200)

Wei Y, Sowers JR, Clark SE, Li W, Ferrario CM \& Stump CS 2008 angiotensin II-induced skeletal muscle insulin resistance mediated by nf-kappab activation via nadph oxidase. American Journal of Physiology: Endocrinology and Metabolism 294 E345-E351. (https://doi. org/10.1152/ajpendo.00456.2007)

Weisinger RS, Stanley TK, Begg DP, Weisinger HS, Spark KJ \& Jois M 2009 Angiotensin converting enzyme inhibition lowers body weight and improves glucose tolerance in c57bl/6j mice maintained on a high fat diet. Physiology and Behavior 98 192-197. (https://doi.org/10.1016/j.physbeh.2009.05.009) Winkler M, Schuchard J, Stölting I, Vogt FM, Barkhausen J, Thorns C, Bader M \& Raasch W 2016 The brain renin-angiotensin system plays a crucial role in regulating body weight in diet-induced obesity in rats. British Journal of Pharmacology 173 1602-1617. (https://doi. org/10.1111/bph.13461)

Xu G, Kaneto H, Laybutt RD, Duvivier-Kali VF, Trivedi N, Suzuma K, King GL, Weir GC \& Bonner-Weir S 2007 Downregulation of glp-1 and gip receptor expression by hyperglycemia possible contribution to impaired incretin effects in diabetes. Diabetes 56 1551-1558. (https://doi.org/10.2337/db06-1033)

Yamauchi T, Kamon J, Waki H, Terauchi Y, Kubota N, Hara K, Mori Y, Ide T, Murakami K, Tsuboyama-Kasaoka N, et al. 2001 The fat-derived hormone adiponectin reverses insulin resistance associated with both lipoatrophy and obesity. Nature Medicine 7 941-946. (https://doi. org/10.1038/90984)

Zhang Z, Liu C, Gan Z, Wang X, Yi Q, Liu Y, Wang Y, Lu B, Du H, Shao J, et al. 2013 Improved glucose-stimulated insulin secretion by selective intraislet inhibition of angiotensin II type 1 receptor expression in isolated islets of $\mathrm{db} / \mathrm{db}$ mice. International Journal of Endocrinology 2013 10. (https://doi. org $/ 10.1155 / 2013 / 319586)$

Zorad S, Dou J-T, Benicky J, Hutanu D, Tybitanclova K, Zhou J \& Saavedra JM 2006 Long-term angiotensin II at1 receptor inhibition produces adipose tissue hypotrophy accompanied by increased expression of adiponectin and ppary. European Journal of Pharmacology 552 112-122. (https://doi.org/10.1016/j.ejphar.2006.08.062)

Received in final form 3 April 2018

Accepted 11 April 2018

Accepted Preprint published online 11 April 2018
C) 2018 Society for Endocrinology Published by Bioscientifica Ltd. Printed in Great Britain 